\title{
Study on Ecological Scheduling of the Xiaolangdi Reservoir Based on the Ecological Needs of Estuarine Fishes
}

\author{
Tian Shimin ${ }^{1}$, Zhao Yi ${ }^{2}$, Wang Yuanjian ${ }^{1}$, Jiang Enhui ${ }^{1 *}$,Yu Shoubing ${ }^{1}$ \\ ${ }^{1}$ Yellow River Institute of Hydraulic Research, Key Laboratory of Yellow River Sediment, Zhengzhou 450003, China \\ ${ }^{2}$ Information Center, Yellow River Conservancy Commission, Zhengzhou 450004, China)
}

\begin{abstract}
The total water amount into the Yellow River estuary is significantly reduced with the construction of a series of reservoirs in the Yellow River, which has a lot of adversely effects on the fishes and fishery resources in the estuary. This research analyzes the impacts of the reservoirs on the runoff and discharge in the Lower Yellow River and the estuary, and pays more attention to the influences of the reduction of water amount on the estuarine ecology and fishes. As a large reservoir nearest to the estuary in the Lower Yellow River, the operation of Xiaolangdi Reservoir plays an important role on the ecological restoration of the lower reaches of the Yellow River and the estuary. Two ecological operation schemes are proposed based on the ecological demands of the estuarine fishes and the actual operation of the Xiaolangdi Reservoir in recent years. One scheme is proposed only on the basis of the estuarine ecological water demands and another scheme takes consideration of ecological water demands and the actual status of the water resources in the Lower Yellow River synthetically. Finally, the feasibility of the two schemes are analyzed according to the actual situation of water storage of the reservoirs in the Yellow River in 2017.
\end{abstract}

River and other rivers.

\section{Introduction}

Conventional reservoir scheduling is intended to satisfy the needs of electricity generation, irrigation, and flood prevention. While promoting unified management and efficient utilization of water resources, conventional reservoir scheduling also disrupts the ecosystems and natural hydrological regime of rivers, thereby producing a succession of eco-environmental problems ${ }^{[1]}$. As people attach increasing importance to ecological environments, various ecological problems of rivers arising from water conservancy projects have gradually become a hot topic of research. Hence, conventional reservoir scheduling, which originally focused on water conservancy and flood prevention, has gradually evolved into ecological scheduling and comprehensive scheduling ${ }^{[2]}$. The existing studies on river ecosystems involve river channels and estuarine areas. However, the studies on ecological scheduling of reservoirs mainly focus on how to satisfy the ecological needs of river channels, and there have been very few studies on ecological scheduling in estuarine areas. Using the Yellow River estuary as the subject of research, this study investigates the ecological scheduling scheme for the Xiaolangdi Reservoir based on the ecological needs of estuarine fishes. The findings of this study can be used as a reference by researchers studying ecological scheduling in estuarine areas of the Yellow

\section{Study area}

At the Yellow River estuary, which is located at the juncture of the Bohai Bay and Laizhou Bay, the freshwater, silt, and nutrient substances carried by the sea-bound runoff of the Yellow River interact with the marine environment of the Bohai Sea. As a result, the waters of the Yellow River estuary along with the adjacent waters become not only the area with the greatest diversity of zooplankton and phytoplankton in the Bohai Sea, but also a spawning ground, feeding ground, nursing ground, and fishing ground for a variety of fishes ${ }^{[3-5]}$. Every year, the months of March to June are the spawning season for the fishes in the Yellow River estuary. The sea-bound runoff in the spawning season determines the area of low-salinity freshwater spawning and the hatching ground in the Yellow River estuary in spring. Owing to recurrent peach floods in the Yellow River, the Yellow River estuary waters historically became a hatching ground that was suitable for the spawning and growth of creatures in a freshwater environment in spring. After a series of reservoirs along the trunk of the Yellow River were put into use, peach floods were reduced remarkably through reservoir scheduling. Owing to the change in the lowsalinity and freshwater environment of the Yellow River estuary waters and adjacent waters, the Yellow River

\footnotetext{
*Corresponding author.
} 
sauries, who require a freshwater habitat, almost died out, and the yield of prawns in the Laizhou Bay also began to decrease significantly in the 1990s. Fig. 1. Variation in the runoff of the Sanmenxia Hydrological Station and Lijin Hydrological Station from March to May after Reservoirs were put into use.

shows the inter-annual variation in the section runoff of the Sanmenxia Hydrological Station and Lijin Hydrological Station from March to May. After the Sanmenxia Reservoir was put into use in 1960, there was a significant decline in the section runoff in the Sanmenxia Hydrological Station and Lijin Hydrological Station from March to May. At the end of 2000, when the Xiaolangdi Reservoir was completed and used for the scheduling of water and silt, increases in the section runoff were observed in the Lijin Hydrological Station from March to May.

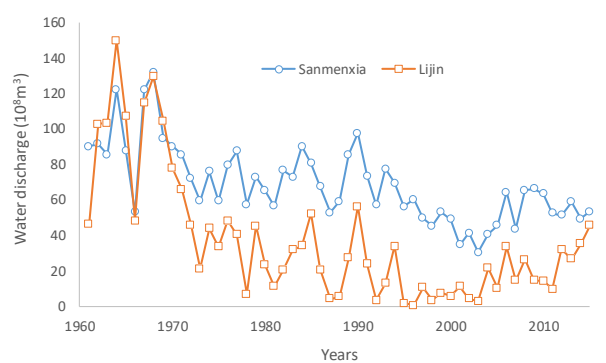

Fig. 1. Variation in the runoff of the Sanmenxia Hydrological Station and Lijin Hydrological Station from March to May after Reservoirs were put into use.

\section{Ecological needs of estuarine fishes}

\subsection{Estuarine fish resources and their ecological habits}

The fishes in the Yellow River estuary are dominated by the river-plain complexes, and fall under two ecological groups: freshwater fishes and estuarine brackish water fishes ${ }^{[7]}$. So far, it has been observed that approximately 39 types of fishes spawn in the Yellow River estuary waters $^{[8]}$, and most of them are migratory fishes. The fishery resource formations in the Bohai Sea and Yellow Sea are characterized by near-shore spawning in lowsalinity estuaries ${ }^{[9-12]}$. The variety and quantity of fish roes and larvae in the Yellow River estuary waters have a direct impact on the replenishment of fish resources across the entire Bohai Sea and Yellow Sea ${ }^{[13]}$.

Every year, the months of March to June are the spawning season and migration season for the fishes in the Yellow River estuary, and the waters in the Yellow River estuary must meet specific requirements for runoff volume, water flow velocity, water depth, and salinity. For example, the spawning grounds for the Yellow River carp must have a water depth greater than $1 \mathrm{~m}$ and a water flow velocity lower than $0.3 \mathrm{~m} / \mathrm{s}$ (slow flow or still water). While juvenile sauries swim from seas to rivers in April to June, they regulate themselves in the salty-fresh water areas of estuaries. Then, the sea-bound runoff has a direct impact on the upstream swimming of shoals. Specifically, if the sea-bound runoff is large, the salinity in the salty-fresh water areas is low, and the upstream swimming shoals are large; furthermore, if the salinity in the salty-fresh water areas is high, the upstream swimming shoals are small. To ensure the survival of juvenile sauries, the water flow velocity should be in the range of 0.4 to $0.5 \mathrm{~m} / \mathrm{s}$. In the migration season for sauries, the water flow velocity should not be higher than $1 \mathrm{~m} / \mathrm{s}$, and the water depth should be greater than $0.6 \mathrm{~m}$. February to May is the season in which juvenile eels migrate from seas to rivers. In the migration season, the water flow velocity should be in the range of 0.3 to $0.5 \mathrm{~m} / \mathrm{s}$, and the water depth should be greater than $1 \mathrm{~m}$. The barracuda and hairy crab of the Yellow River estuary are the species peculiar to the Yellow River estuary. They spawn, hatch, and grow up at all times in the Yellow River estuary. Their spawning season includes May and June, and their spawning grounds must have a water depth in the range of 1 to $10 \mathrm{~m}$, and a salinity in the range of $27 \%$ to $29 \%$. In addition, other fishery species of the Yellow River estuary (for example, cynoglossus semilaevis, cynoglossus semilaevis (Spanish mackerel), and portunid) have a remarkable reliance on the runoff volume and diluted water volume in the estuary.

\subsection{Impact of diluted water in the Yellow River estuary on fishery resources}

The salinity of sea water has a direct impact on the growth and reproduction of marine organisms. The sea-bound diluted water in the Yellow River estuary affects not only the ecosystem in the estuary, but also the grand ecosystems of the Bohai Sea and Yellow Sea. The large flow process serves to expand the scope of diluted water. According to the previous monitoring data, the distribution scope of diluted water in the Yellow River estuary expands significantly during the period when water and silt are regulated by the Xiaolangdi Reservoir as compared with the period when there is no regulation. Specifically, the 29-psu isosalinity line stretches as north as the open sea of the Dongying Harbor $40 \mathrm{~km}$ away from the estuary (the offshore distance is up to 15 to $20 \mathrm{~km}$ ) and stretches as south as the Xiaoqing River estuary. In addition, there is a significant difference between surface water and bottom water.

The sea-bound diluted water has an important regulatory effect on the phytoplankton, zooplankton, zoobenthos, and fishes in the Yellow River estuary waters and adjacent waters. Phytoplankton are the primary producers in the marine food chain. Their quantitative distribution and seasonal variations are closely associated with the concentration distribution of nutrient salts in waters and its variation. Zooplankton are the secondary producers in the marine food chain. Their biomass and productivity usually affect their fluctuation in fishery resources. Every year, the Yellow River carries large quantities of terrestrially-sourced nutrient substances into seas. As a result, the Yellow River estuary waters and adjacent waters become not only the waters with the greatest diversity of plankton across the Bohai Sea, but also a concentrated distribution area for a variety of juvenile fishes. Besides, the high productivity of the estuarine waters breeds large quantities of biological organisms, which provide ample food for the growth and 
fattening of juvenile fishes; owing to the low-salinity water environment, there is a reduction in the energy required for the osmotic adjustment of the euryhaline fishes living in the waters, thereby facilitating the survival of juvenile fishes ${ }^{[14]}$. Influenced by the sharp decline in the runoff volume of the Yellow River, the quantity of phytoplankton cells in the Yellow River estuary around 2000 has decreased by nearly one order of magnitude as compared with that in the 1980 s, thereby affecting the high-end biological fishes in the food chain.

\subsection{Estuarine ecological needs}

In the mid-1980s, the State Aquatic Product General Bureau gave an estimation of the ecological water demand of the fishery industry in the Yellow River estuary, and believed that, to satisfy the growth needs of fishes and shrimps in the Yellow River estuary, the total sea-bound runoff in April to June should be approximately 6 billion $\mathrm{m}^{3}$ in the estuary (in a dry year, a runoff of approximate 2 billion $\mathrm{m}^{3}$ can be discharged concentratedly in April) $)^{3[7,15]}$. Jiang Xiaohui et al. ${ }^{[7]}$ took anchovies, half-fin anchovies, and sauries as the prioritized protection species, and took the growth period of roes and juvenile fishes as the critical life stage. For most of the anchovies, half-fin anchovies, and sauries, the spawning season and migration season are in April to June, and for spawning to occur, the salinity of the offshore spawning grounds should be in the range of 23.5 to $30.71 \mathrm{psu}$. Based on the correlation between the sea-bound runoff and salinity, the optimal ecological water demand in the Yellow River estuary is $1,800 \mathrm{~m}^{3} / \mathrm{s}$ in April and $530 \mathrm{~m}^{3} / \mathrm{s}$ in May and June.

\section{Ecological scheduling schemes}

\subsection{Scheduling scheme for the years with a high degree of guarantee of ecological runoff}

From March to May in 2014 and 2015, the runoff discharged from the Xiaolangdi Reservoir was quite large. In March 2014, the runoff velocity in the Xiaolangdi Reservoir remained at the level of 1,344 $\mathrm{m}^{3} / \mathrm{s}$; from March to May in 2014, the runoff discharge reaching the Lijin Hydrological Station was 3.194 billion $\mathrm{m}^{3}$. As a result, the density of roes and density of juvenile fishes in the Yellow River estuary increased by two to eight times as compared with those in 2007 and 2009. From March to May in 2015, the sea-bound freshwater volume was 4.585 billion $\mathrm{m}^{3}$. As a result, the density of roes in the Yellow River estuary increased by three to ten times as compared with that in 2007 and 2009.

We compared the runoff process in the Lijin Hydrological Station from March to May in 2014 and 2015 and that from March to May in previous years (take 2007 and 2009 as the typical years). As shown in Figure 2, from late March to late May in 2007 and 2009, the runoff in the Lijin Hydrological Station was relatively small (basically below $200 \mathrm{~m}^{3} / \mathrm{s}$ ) in the concentrated spawning season and migration season. This is the dominant factor that affects the density of roes and density of juvenile fishes. Hence, it is necessary to increase the sea-bound runoff in the Yellow River estuary moderately from late March to late May or in April and May, so as to increase the density of roes and juvenile fishes in the estuary, and thus increase the fishery yield and ratio of fishery economy.

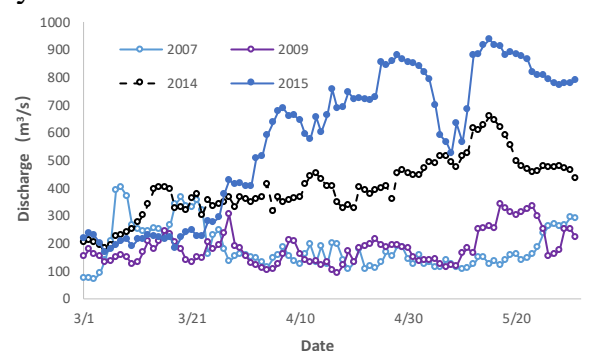

Fig. 2. Comparison between the runoff process in the Lijin Hydrological Station in 2014 and 2015 and that in 2007 and 2009.

In this study, we compared the runoff process in the Lijin Hydrological Station from 2011 to 2015. From early April to late April (about 25 days), the runoff volume was significantly small in 2011 to 2013. From late April to early May (about seven days), the runoff process in 2012 and 2013 was approximate to that in 2014 and 2015. From early May to late May, the runoff volume decreased significantly in 2011 to 2013, and in late May of 2012, the runoff volume increased significantly. However, the fishery yield in 2011 to 2013 was somewhat smaller than that in 2014 and 2015. Therefore, this study believes that the density of roes and juvenile fishes can be improved significantly when the runoff volume remains at the level of 2.3 billion $\mathrm{m}^{3}$ (in April and May of 2014) and the average runoff velocity is greater than $400 \mathrm{~m}^{3} / \mathrm{s}$ (in April and May of 2014) in April and May.

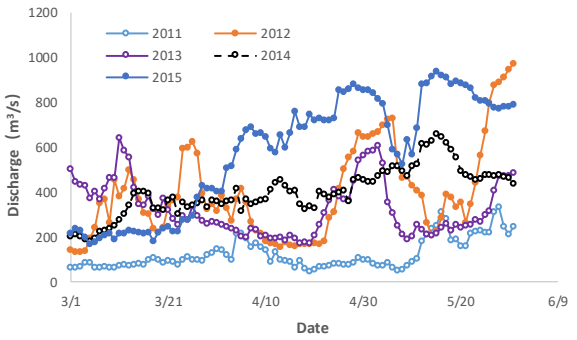

Fig. 3. Runoff process in the Lijin Hydrological Station from 2011 to 2015 .

\subsection{Scheduling scheme of the Xiaolangdi Reservoir based on estuarine ecological needs}

Based on the above analysis, the runoff volume and runoff velocity in the Yellow River estuary in April and May must not be less than specific critical values. Accordingly, this study presents two ecological scheduling schemes for April to June of 2017.

\subsubsection{Scheduling scheme that fully meets the estuarine ecological needs}

From April to June during the years 2012 to 2015, the average runoff volume was 4.885 billion $\mathrm{m}^{3}$. According to the suggestions of the fishery authorities, a runoff of 2 billion $\mathrm{m}^{3}$ should be discharged concentratedly in April, and the minimum runoff velocity of $530 \mathrm{~m}^{3} / \mathrm{s}$ (the runoff 
volume is 2.793 billion $\mathrm{m}^{3}$ ) should be kept in May and June. In this scheduling scheme, the total water demand in April to June is 4.793 billion $\mathrm{m}^{3}$, which is approximately the average runoff volume in April to June during the years 2012 to 2015. In this scheduling scheme, the runoff discharge from the Xiaolangdi Reservoir in April to June is approximately 10 billion $\mathrm{m}^{3}$, which is equivalent to the average runoff discharge from the Xiaolangdi Reservoir during the years of 2012 to 2015 .

\subsubsection{Scheduling scheme for the years with a high degree of guarantee of ecological runoff}

According to the scheduling mode for 2014 and 2015, the average velocity of runoff discharge from the Xiaolangdi Reservoir in March was $1,344 \mathrm{~m}^{3} / \mathrm{s}$ and $1,280 \mathrm{~m}^{3} / \mathrm{s}$, respectively. However, the average runoff velocity in the Lijin Hydrological Station was $305 \mathrm{~m}^{3} / \mathrm{s}$ and $251 \mathrm{~m}^{3} / \mathrm{s}$, respectively, in March, $386 \mathrm{~m}^{3} / \mathrm{s}$ and $691 \mathrm{~m}^{3} / \mathrm{s}$, respectively, in April, and $459 \mathrm{~m}^{3} / \mathrm{s}$ and $649 \mathrm{~m}^{3} / \mathrm{s}$, respectively, in May and June. Under this runoff process, the density of roes and juvenile fishes increase remarkably. Considering that the spawning and migration of fishes call for large-pulse stimuli and reminders, this study recommends that the Xiaolangdi Reservoir should discharge the runoff at the full velocity of $1,800 \mathrm{~m}^{3} / \mathrm{s}$ in early and middle April (prior to the $15^{\text {th }}$ day). Judging by the relationship between the average runoff velocities in the Xiaolangdi Reservoir and Lijin Hydrological Station (the former is approximately 3.8 times as much as the latter), the velocity of runoff discharge reaching the Lijin Hydrological Station is $474 \mathrm{~m}^{3} / \mathrm{s}$, falling between the level of 2014 and that of 2015. In middle and late April, the Xiaolangdi Reservoir should discharge the runoff according to the actual condition. When the Xiaolangdi Reservoir regulates water and silt normally in May and June, the average runoff velocity is approximately 669 $\mathrm{m}^{3} / \mathrm{s}$ (during the years 2010 to 2015 ), which can fully meet the ecological water demand. In this scheduling scheme, the runoff volume in the Lijin Hydrological Station is 0.614 billion $\mathrm{m}^{3}$ in early and middle April and adds up to 3.526 billion $\mathrm{m}^{3}$ in May and June. From April to June (excluding mid and late April), the total runoff volume in the Lijin Hydrological Station is 4.14 billion $\mathrm{m}^{3}$, a decrease of 0.6 billion $\mathrm{m}^{3}$ as compared with the average runoff volume over many years.

\subsection{Analysis of scheme feasibility}

Fig. 4. Runoff volume in the Lijin Hydrological Station in different months from 2011 to 2015.

shows the runoff volume in the Lijin Hydrological Station in different periods (specifically, March to May, April and May, April to June, April to July, and April to October) during the years 2011 to 2015 . We can see that, among the five years (2011 to 2015), the runoff volume is quite small in April to June, April to July, and April to October in 2014 and 2015. Nevertheless, favorable ecological benefits and fishery harvests are accomplished through optimal scheduling of water and silt. Therefore, in other years with ample runoff in April to June, the same or approximate ecological benefits can be accomplished through optimal scheduling.

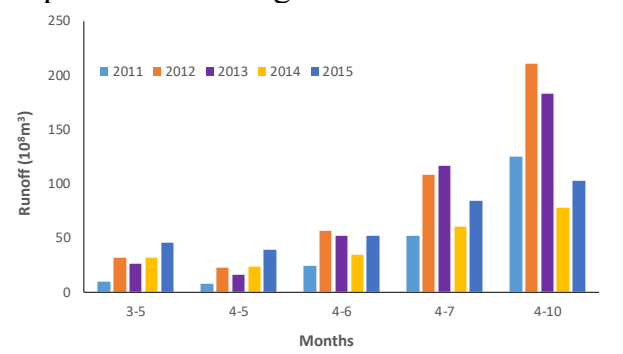

Fig. 4. Runoff volume in the Lijin Hydrological Station in different months from 2011 to 2015 .

Using 2017 as a typical year, we analyze the feasibility of the scheduling schemes above. Figure 5 and Figure 6 show the water storage and water level of the Xiaolangdi Reservoir and Longyangxia Reservoir during the years of 2012 to 2017, respectively. Both the water storage and water level of the Xiaolangdi Reservoir during these years are greater than those in 2014. By March $21^{\text {st }}$, the water storage of the Xiaolangdi Reservoir is 5.951 billion $\mathrm{m}^{3}$, an increase of nearly 0.7 billion $\mathrm{m}^{3}$ as compared with that in 2014. Therefore, both of the ecological scheduling schemes above are feasible. At present, both the water storage and water level of the Longyangxia Reservoir are greater than those in 2016, but less than those in 2012 to 2015. In the process of ecological scheduling, it is necessary to pay attention to the water storage of the upstream reservoir. Otherwise, the insufficiency of subsequent water storage will affect irrigation and electricity generation.

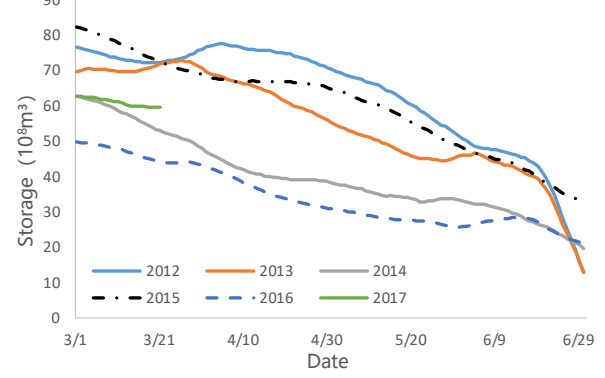

a) Water storage

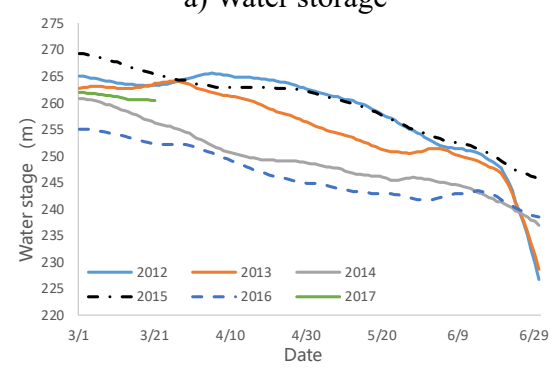

b) Water stage

Fig. 5. Water storage and water level in the Xiaolangdi Reservoir from 2012 to 2016.

Based on the above analysis, the second scheduling scheme is recommended for 2017 , when the water storage of the Longyangxia Reservoir is not sufficient. In addition, the first scheduling scheme is recommended in the years with ample water storage. Moreover, the two scheduling schemes can be optimized reasonably to ensure the stability of the estuarine ecosystem and fishery resources. 


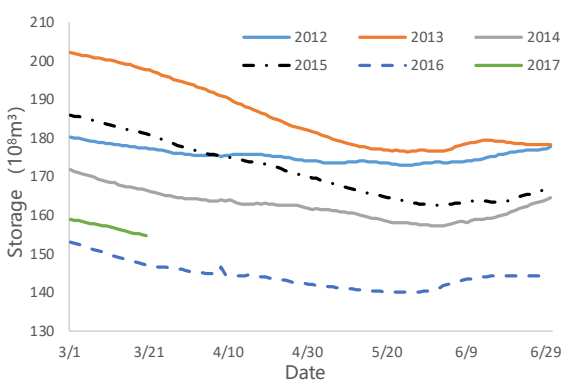

a) Water storage

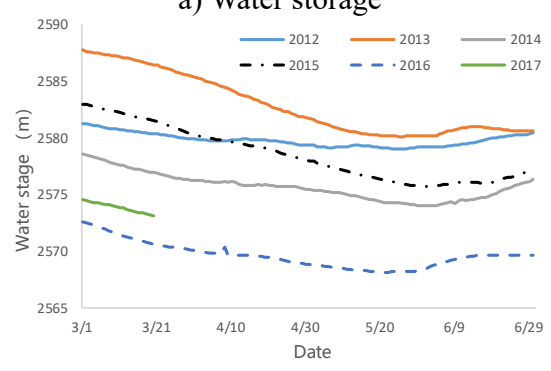

b) Water stage

Fig. 6. Water storage and water level in the Longyangxia Reservoir from 2012 to 2016

\section{Conclusions}

Spring is the spawning and nursing season for the fishes in the Yellow River estuary. The sea-bound runoff in the Yellow River estuary in spring has a significant impact on the spawning and migration of the estuarine fishes. In addition, the fishery productivity in the Yellow River estuary waters and adjacent waters is determined by the degree to which the ecological needs of estuarine fishes are satisfied. By comparing the runoff process in 2007 and 2009 and that in 2014 and 2015 for corresponding periods, we find that there is a significant increase in the density of roes and juvenile fishes in the Yellow River estuary waters owing to an increase in the sea-bound runoff in spring. This study presents two ecological scheduling schemes, which are respectively based on the ecological needs of estuarine fishes and the actual condition in the lower reaches of the Yellow River. An optimal scheduling scheme can be selected from the two according to the water storage and water level of the reservoirs in the trunk of the Yellow River in spring. Specifically, the first scheduling scheme is recommended when the water storage is sufficient; the second scheduling scheme is recommended in the years with normal water storage.

\section{Acknowledgment}

This study was supported by the National Key Research and Development Program of China (2018YFC0407401) and the National Natural Science Foundation of China (NSFC, No. 51539004 ).

\section{References}

1. XU Zongxue, WU Wei, YU Songyan. Ecological baseflow: Progress and challenge [J]. Journal of Hydroelectric Engineering, 2016(04):1-11. (in Chinese)
2. HUANG Qiang, ZHAO Menglong, LI Ying. Advancements in studies on reservoir ecological operation [J].Journal of Hydroelectric Engineering, 2017(03):1-11. (in Chinese)

3. JIAO Yumu, ZHANG Xinhua, LI Huixin. Influence on fish diversity in the sea area of the HUANGHE River Estuary by the cutoff of water supply.[J]. Transaction of Oceanlogy and Limnology, 1998(04):48-53. (in Chinese)

4. LIU Shuang, ZHANG Ji-min, LENG Yu. Species and distribution characteristics of fish eggs and larvae at the Yellow River Estuary [J]. Marien Science Bulletin, 2011(06):662-667. (in Chinese)

5. LU Zhenbo, LI Fan, QU Yebing, ZHANG Huanjun, XU Bingqing, WANG Tiantian. Fish community diversity in the Huanghe estuary and its adjacent area in summer,2010[J].Progress in Fishery Science, 2013(02):10-18. (in Chinese)

6. HOU Suzhen, Wang Ping. Influence of spring flood on Tongguan Elevation [J]. Journal of Sediment Research, 2005(01):53-56. (in Chinese)

7. JIANG Xiaohui, HE Hongmou, QU Shaojun, etc. The influence of the Yellow River main flow reservoir on the river ecosystem and its ecological operation. [M]. Zhengzhou:Yellow River conservancy press, 2012: 284. (in Chinese)

8. YANG Jiming, LI Jun. Progress of Chinese marine ichthyology in the last 15 years [J]. Studia Marina Sinca, 1995(00):297-310. (in Chinese)

9. BIAN Xiaodong, ZHANG Xiumei, GAO Tianxiang, etc. Category composition and distributional patterns of ichthyoplankton in the Yellow River estuary during spring and summer 2007 [J]. Journal of Fishery Science of China, 2010(04):815-827. (in Chinese)

10. ZHAO Chuangang, LIU Xiaoshun, ZENG Bingguang, et al. Fishery resources in Chinese ocean[M]. HangZhou, Zhejiang Science and Technology Press, 1990. (in Chinese)

11. Chen Dagang. Fishery ecology in the Yellow sea and Bohai sea [M]. Beijing, Maritime Press, 1991. (in Chinese)

12. Fisheries Bureau, Ministry of Agriculture. Investigation and division of fishery resources in Huanghai and Bohai District [M]. Beijing, Maritime Press, 1990. (in Chinese)

13. ZHU Xinhua, MIAO Feng, LIU Dong, etc. Spatiotemporal pattern and dominant component of fish community in the Yellow river estuary and its adjacent waters[J]. Studia Marina Sinica, 2001(00):141-151.

14. POTTER I C, BECKLEY L E, WHITFIELD A K, et al. Comparisons between the roles played by estuaries in the life cycles of fishes in temperate Western Australia and Southern Africa[J]. Environmental Biology of Fishes, 1990(No.1-4):143-178. (in Chinese)

15. NI Jinren, JIN Ling, ZHAO Yean, etc. Minimum water demand for ecosystem protection in the Lower Yellow River [J]. Journal of Hydraulic Engineering, 2002(10):1-7. (in Chinese) 